Ann. Biol. anim. Bioch. Biophys, I970, 10 (I), I75-I77.

NOTE

\title{
INFLUENCE DE LA FLORE INTESTINALE SUR L'UTILISATION DIGESTIVE DES ACIDES GRAS CHEZ LE RAT
}

\author{
Y. DEMARNE, E. SACQUET (*), J. FLANZY et H. GARNIER (*) \\ et A.-C. FRANÇOIS \\ Station centrale de Nutrition, \\ Centre national de Recherches zootechniques, 78 -Jouy-en-Josas \\ Institut national de la Recherche agronomique \\ (*) Service des animaux sans germes, 91 - Gif-sur-Yvette \\ Centre national de la Recherche scientifique
}

L'emploi des animaux axéniques a permis de mettre en évidence l'influence de la flore intestinale sur la digestion et l'absorption d'un certain nombre de nutriments. Ainsi, des sucres tels que le xylose, des acides aminés tels que la méthionine, et des vitamines comme la thiamine sont absorbés plus rapidement par l'animal axénique que par l'animal holoxénique (HanNeGan, 1963 ; Gordon et al., I960; Herskovic et al., I967). Cependant, l'influence de la flore intestinale sur l'utilisation digestive des acides gras reste peu connue.

Deux groupes de 6 rats consanguins âgés de 4 semaines ont été formés. Un des deux groupes était axénique. La durée de l'expérience a été d'un mois. Pendant cette période, les animaux ont reçu un régime contenant $\mathrm{I} 3,3$ p. Ioo de matières grasses et 5,4 p. Ioo de cellulose. Les lipides de la ration provenaient d'un mélange d'huiles, choisies a fin de couvrir toute la série des acides gras aliphatiques saturés et insaturés, depuis l'acide laurique $\left(C_{12}\right)$ jusqu'à l'acide béhénique $\left(C_{22}\right)$. Les acides gras saturés contenant au moins 16 atomes de carbone formaient $42 \mathrm{p}$. Ioo des acides gras dosés.

Les analyses ont été réalisées à partir de $\mathrm{I} 2$ échantillons de fèces récoltés chaque semaine. Après avoir été séchées, les fèces ont été pesées. Pour une quantité de matières sèches ingérées sensiblement identique, le poids de matières sèches excrétées par les animaux axéniques était de 35 p. Ioo supérieur à celui excrété par les animaux holoxéniques. Ceci semble dû, au moins en partie, à la faible digestibilité de la cellulose en absence de micro-organismes (EvRARD et al., 1964).

Les matières grasses ont été analysées selon la méthode de Toullec et al. (I968). Nous avons pu ainsi déterminer la quantité globale de matière grasse excrétée, et isoler les fractions solubles et insolubles des acides gras fécaux telles que les définissent ces auteurs.

Dans les fèces des animaux holoxéniques, $7 \mathrm{r}$ p. roo des acides gras se trouvent sous forme insoluble. Par contre, dans le cas des animaux axéniques, 75 p. Ioo des acides gras se trouvent sous forme soluble. 
L'analyse par chromatographie en phase gazeuse des acides gras des diverses fractions montre que, chez le Rat holoxénique, la fraction insoluble contient $83 \mathrm{p}$. Ioo d'acides gras saturés longs $\left(\geqslant \mathrm{C}_{10}\right)$, contre $5 \mathrm{I}$ p. roo dans la fraction soluble. Chez l'animal axénique, la composition en acides gras des deux fractions est sensiblement la même. Chez le Rat holoxénique, la formation des savons insolubles se fait donc essentiellement à partir des acides gras longs et saturés.

Parallèlement à cet ensemble de résultats, nous avons noté que la digestibilité globale apparente des matières grasses de notre régime est améliorée lorsque l'animal est axénique ( $7^{2} \mathrm{p}$. Ioo contre 68,5 p. roo).

Les calculs que nous avons effectués afin d'étudier le coefficient d'utilisation digestive des différents acides gras du régime nous permettent de conclure à une meilleure digestibilité des acides palmitique $\left(\mathrm{C}_{16}\right)\left(63 \mathrm{p}\right.$. Ioo contre $55,5 \mathrm{p}$. 100) et stéarique $\left(\mathrm{C}_{16}\right)(57, \mathrm{I}$ p. roo contre 50 , I p. Ioo chez l'animal axénique). Or, FLANzy et al. (1968) ont précisément montré que ces acides gras étaient mal absorbés et qu'ils étaient en majeure partie précipités sous forme insoluble dans les fèces. On peut donc penser que chez l'animal axénique, qui produit moins de savons insolubles, la meilleure digestibilité apparente des matières grasses est essentiellement due à une augmentation de l'utilisation digestive des acides gras saturés et longs qui sont moins insolubilisés durant le transit intestinal.

D'après les travaux de Scribante et Favarger (1954) et de Werner (1965), l'utilisation digestive de l'acide palmitique varie en fonction de la teneur en acide stéarique du régime et réciproquement. On ne sait pas quelle est l'inflence des acides gras très longs $\left(\geqslant C_{20}\right)$ sur l'utilisation digestive des autres acides gras. C'est pourquoi, nous nous sommes proposés, dans une autre série d'expériences, de réaliser un travail identique à celui dont nous rapportons ici les résultats, mais en éliminant du régime les acides gras ayant plus de 20 atomes de carbone. Les résultats de ces travaux seront publiés ultérieurement.

\title{
Rę̧u pour publication en octobre 1969.
}

\author{
SUMMARY \\ INFLUENCE OF THE FLORA OF THE INTESTINE ON \\ DIGESTIVE UTILIZATION OF FATTY ACIDS BY RATS
}

In rats overall apparent digestibility of saturated fats is better in germ-free animals. Parallel to this it can be seen that in faeces of germ-free rats the amount of insoluble soaps estimated is less than in faeces of conventional rats. The better apparent digestibility of saturated fats by germ-free animals can be attributed to a smaller degree of insolubilization of palmitic and stearic acids during passage through the intestine.

\section{RÉFÉRENCES BIBI,IOGRAPHIQUES}

Evrard E., Hoet P. P., Eyssen H., Charlier H., Sacquet E., I964. Faecal lipids in germ-free and conventionnal rats. Brit. J. exp. Pathol., 45, 409-4I4.

Flanzy J., Rérat A., François A-C., I968. Étude de l'utilisation digestive des acides gras chez le Porc. Ann. Biol, anim. Bioch. Biophys, 8, 537-548.

Gordon H. A., Bruckner-Kardoss E., KAN D., I960. Effects of normal microbial flora on structural and absorptive characteristics of the intestine. In : Abstr. 5th Internat. Congr. Nutrition, Washington, ig6o, 21. Cité par Tennant B., Reina-Guerra M., Harrold D., Goldman M., ig69. Infuence of microorganismes on intestinal absorption : oleic acid ${ }^{131}$ and triolein ${ }^{231}$ absorption by germfree and conventionalized rats. $J$. Nutr., $97,65-69$.

HeneghaN J. B., 1963. Influence of microbial flora on xylose absorption in rats and mice. Amer. J. Physiol., 205, 4I7-420.

Herskovic T., Katz J., HLoch M. H., Spencer R. P., Spiro H. M., I967. Small intestinal absorption and morphology in germ-free, monocontaminated, and conventionalized mice. Gastroentero$\log y, 52$, I 136 . 
Scribante P., Favarger P., r954. Étude de la digestibilité de l'acide stéarique et de ses esters glycéridiques chez le Rat. Helv. Physiol. Pharmacol. Acta, 12, 74-89.

Toullec R., Flanzy J., Rigaud J., 1968. Dosage des lipides des fèces. Ann. Biol. anim. Bioch. Biophys., 8, 28I-289.

WERnER M., I965. Vergleichende Bilanzuntersuchungen der Fettverdauung mit chemischen Methoden und radioaktiven Lipiden. Helv. med. Acta, 32, 457-46o. 